\title{
Distracción osteogénica del maxilar y manejo ortodóncico integral en paciente con síndrome de Pfeiffer. Reporte de caso
}

\section{Maxillary osteogenic distraction and comprehensive orthodontic treatment in a patient with Pfeiffer syndrome. A case report}

\begin{abstract}
Resumen
Síndrome de Pfeiffer es una craneosinostosis de herencia autosómica dominante, cuyas manifestaciones clínicas son tanto a nivel cráneofacial como en extremidades superiores e inferiores. El tratamiento para estos pacientes debe ser efectuado por un equipo multidisciplinario y representa un gran desafío para los profesionales de la salud. El objetivo de este artículo es exponer el caso de una paciente adolescente diagnosticada con síndrome de Pfeiffer, que presentaba hipoplasia maxilar severa, maloclusión de Clase III y overjet negativo; tratada con distracción osteogénica usando dispositivo RED (rigid external distractor) asociado a aparatología ortodóncica fija. Los resultados cumplieron con las expectativas terapéuticas y estéticas de la paciente, mostrando estabilidad en la evaluación 20 meses post tratamiento.
\end{abstract}

Palabras clave: Acrocefalosindactilia; Ortodoncia; Osteogénesis por distracción; Hueso maxilar (fuente: DeCS BIREME).

\begin{abstract}
Pfeiffer's syndrome is an autosomal dominantly inherited craniosynostosis, its clinical features are both at craniofacial level and upper and lower limbs. The treatment must be carried out by a multidisciplinary team and represents a great challenge for health professionals. The aim of this article is to present the case of a teenage patient diagnosed with Pfeiffer's syndrome, who had severe maxillary hypoplasia, class III malocclusion and negative overjet; treated by osteogenic distraction with a RED (rigid external distractor) associated with fixed orthodontic appliances. The results reached the patient's therapeutic and esthetic expectations and showed stability at 20 months posttreatment.
\end{abstract}

Keywords: Acrocephalosyndactylia; Orthodontics; Distraction osteogenesis; Maxilla (source: MeSH NLM).

\section{Caso Clínico}

Noemí Leiva ${ }^{1, a, b}$, Carolina Stange ${ }^{1, a}$, Francisca Ayala ${ }^{1, a}$ Vanessa Fuentes ${ }^{1, a}$, Carmen Gloria Morovic ${ }^{1, c}$

${ }^{1}$ Universidad de Chile, Facultad de Odontología, Unidad de Malformación Cráneofacial, Santiago, Chile.

a Cirujana Dentista.

${ }^{\mathrm{b}}$ Especialista en Ortodoncia y Ortopedia Maxilofacial. ${ }^{c}$ Cirujano Plástico Pediátrico. Especialista en Malformación Cráneofacial.

\section{Correspondencia:}

Noemí Leiva

Correo electrónico: leivanoemi@yahoo.com Sergio Roberto Livingstone Pohlhammer 943, Santiago, Chile.

\section{Coautores: \\ Carolina Stange \\ carostange@hotmail.com \\ Francisca Ayala \\ francisca@ayalajimenez.com \\ Vanessa Fuentes \\ vane.fuentes.f@gmail.com \\ Carmen Gloria Morovic \\ cmorovic@gmail.com}

\section{Editor:}

Aron Aliaga-Del Castillo

Universidade de São Paulo, Brasil.

Conflicto de intereses: los autores declaran no tener conflictos de interés.

Fuente de financiamiento: ninguna.

Recibido: 23/01/19

Aceptado: 17/05/19

Publicado: 12/09/19 


\section{Introducción}

El síndrome de Pfeiffer (SP) o acrocefalosindactilia tipo $\mathrm{V}$, corresponde a una patología de herencia autosómica dominante, cuya incidencia es de 1/100 000 nacidos vivos ${ }^{1}$. Es genéticamente heterogéneo; puede deberse a mutaciones en el gen FGFR1, situado en el cromosoma ocho, o en el gen FGFR2, situado en el cromosoma diez. Ambos son receptores del factor de crecimiento fibroblástico ${ }^{2}$.

Se caracteriza por la presencia de diferentes grados de craneosinostosis, frente ancha, nariz pequeña con puente deprimido, falange distal del pulgar y del primer dedo del pie más ancha, hipertelorismo ocular, proptosis y sindactilia parcial en extremidades ${ }^{3,4}$. Sus alteraciones orales y dentarias incluyen hipoplasia del tercio medio facial, paladar profundo, dientes natales, microdoncia, maloclusión de Clase III, mordida cruzada, mordida abierta anterior, agenesias múltiples y apiñamiento dentario ${ }^{5,6}$.

En 1993, Cohen lo clasificó, basado en la severidad de sus manifestaciones craneofaciales y otras anomalías asociadas al síndrome, en tres subtipos ${ }^{7,8}$ :

- Tipo 1: o "clásico", es la forma con mejor pronóstico. Además de exhibir las características clínicas señaladas previamente, los pacientes pueden presentar fusión de vértebras cervicales y anomalías viscerales, como malrotación intestinal o síndrome de Prune Belly. Los pacientes con síndrome de Pfeiffer tipo 1 presentan habitualmente un buen crecimiento cerebral y desarrollo neurológico e intelectual normal.

- Tipo 2: se caracteriza por su "cráneo en trébol" (Kleeblattschädel), producto de la fusión prematura de la mayoría de las suturas craneales, exceptuando la metópica y la escamosa. Presenta limitación en el crecimiento cerebral, hidrocefalia y hernia del tronco cerebral. Otras características asociadas son la proptosis ocular acentuada, anquilosis o sinostosis radio-ulnar, alteraciones respiratorias y complicaciones neurológicas.

- Tipo 3: similar al tipo 2, pero sin cráneo en trébol. Tanto el tipo 2 como el tipo 3 poseen un pronóstico reservado y riesgo elevado de mortalidad temprana.

Su diagnóstico se basa en un adecuado examen físico en conjunto con el análisis molecular de los genes FGFR ${ }^{2}$. Mutaciones en el gen FGFR1 son más prevalentes en el tipo 1; mientras que las del gen FGFR2 lo son en sus fenotipos más severos (tipo 2 y 3 ).

El diagnóstico diferencial debe realizarse con respecto a otros síndromes asociados a craneosinostosis y mutaciones de genes FGFR, como Apert, Crouzon, Muenke, Jackson-Weiss y Beare-Stevenson ${ }^{1,4}$.

En la actualidad, el manejo del síndrome de Pfeiffer es en gran parte sintomático y comienza desde una temprana edad; consiste en una serie de intervenciones quirúrgicas destinadas a corregir los defectos esqueléticos asociados, con el fin de mejorar la calidad de vida de los pacientes afectados. Dentro del equipo multidisciplinario, el ortodoncista cumple un rol fundamental en la corrección de las alteraciones craneofaciales, siendo la distracción ósea una de las técnicas más utilizadas para el tratamiento de la hipoplasia del tercio medio facial, característica común en estos pacientes ${ }^{6,8}$.

En 1997, Polley y Figueroa ${ }^{9}$ introdujeron la técnica de avance maxilar mediante un distractor rígido externo o RED (por sus siglas en inglés rigid external distractor). Este dispositivo permite avances del tercio medio facial mayores a los que se pudiesen obtener a través de una osteotomía Le Fort III. Además, el tratamiento puede iniciarse a una edad más temprana, disminuyendo así las posibles repercusiones en el desarrollo psicosocial del paciente. Otras ventajas asociadas a esta técnica son: el desarrollo del tejido blando adyacente a los segmentos distraídos; neoformación de hueso en las zonas de osteotomías, lo que reduce la necesidad de injerto óseo a futuro; mejor control tridimensional durante la distracción; capacidad para modificar el vector fuerza según cada caso y no requiere de una cirugía mayor para retirar el dispositivo después de la fase de consolidación ${ }^{10}$.

El objetivo de ese este artículo es presentar el manejo ortodóncico integral de una paciente con síndrome de Pfeiffer, a través de distracción osteogénica del tercio medio facial mediante dispositivo RED en conjunto con aparatología fija multibrackets, cuyo resultado cumplió con las expectativas terapéuticas y estéticas de la paciente.

\section{Reporte del caso}

Diagnóstico. Paciente sexo femenino, producto de una segunda gestación de padres sanos, nació a las 38 semanas con un peso de 3450 gramos, talla de $49 \mathrm{~cm}$ y APGAR 9. Presentaba hidrocefalia externa benigna, fascie atípica, nariz pequeña, severa retrusión del tercio medio facial, estrabismo divergente, manos con discreta alteración en la dirección del pulgar y primer dedo de los pies con desviación radial y con falanges distales anchas. A los 12 meses de edad se le diagnosticó con síndrome de Pfeiffer tipo 1, ingresando a tratamiento.

Durante su primera infancia fue sometida a diversas cirugías correctivas por parte del equipo de neurocirugía y cirugía plástica; al año y tres meses se realizó avance fronto-orbitario y del borde orbitario bilateral y a los cuatro años recibió cirugía de miringotomía y adenoidectomía. Su desarrollo psicomotor y neurológico fue normal y acorde a su edad.

Debido a la retrusión del tercio medio facial y diversas alteraciones oclusales, fue derivada a los siete años a la especialidad de Ortodoncia, para tratamiento.

Al examen extraoral, presentaba un tipo facial braquifacial, proptosis, hipertelorismo e incompetencia labial; perfil cóncavo y relación esqueletal de Clase III (Figura 1). Intraoralmente se observaba dentición mixta segunda fase, relación de molares en Clase III, mordida cruzada bilateral, mordida cruzada anterior con un overjet de $-12 \mathrm{~mm}$, mordida abierta anterior con un overbite de 
- $4 \mathrm{~mm}$, apiñamiento dentario severo y agenesias múltiples (Figura 2).

En la radiografía panorámica se confirmó la agenesia de premolares superiores e inferiores, con excepción de los diente 1.5, 2.5 y 4.5 (Figura 3). La reconstrucción tridimensional de tomografía computarizada Cone Beam (TCCB), evidenció craneosinostosis bicoronaria y bitémporo parietal junto con braquicefalia (Figura 4).
Objetivos del tratamiento. Los principales objetivos fueron corregir la hipoplasia del tercio medio a través del avance maxilar, eliminar la proptosis ocular, aumentar el diámetro transversal de la maxila y mejorar parámetros dentarios y oclusales.

Tratamiento. Se planificó la preparación ortodóncica de la paciente para realizar distracción osteogénica mediante un dispositivo RED, asociado a aparatologia

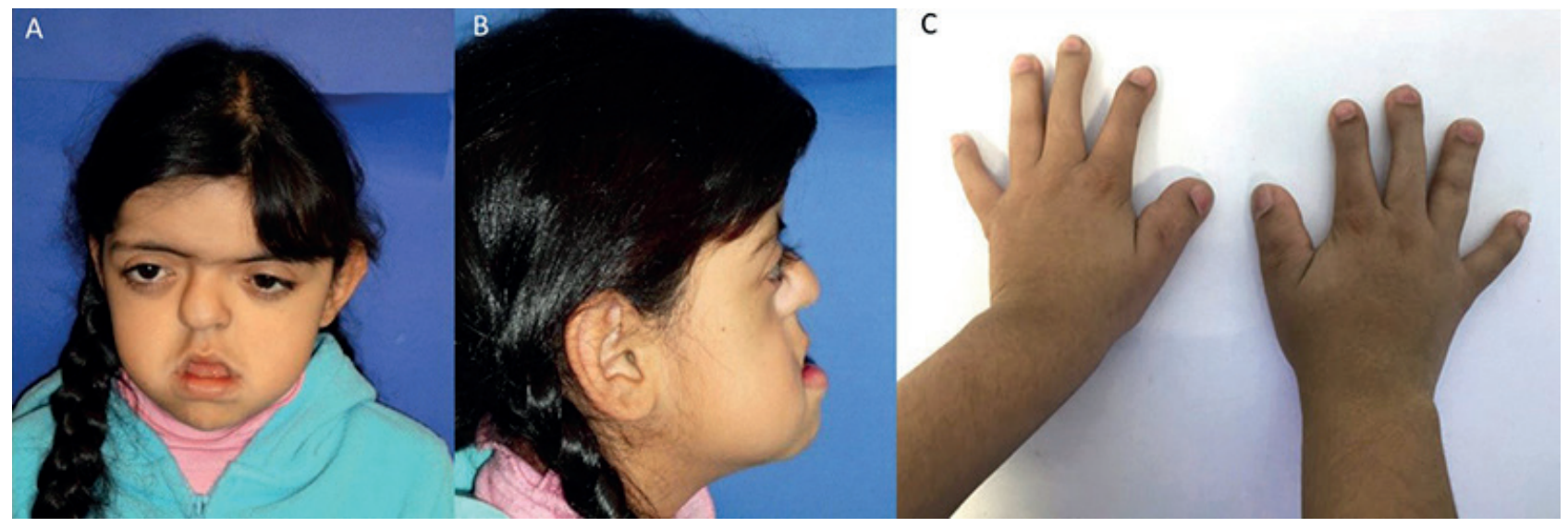

Figura 1. Fotografías extraorales iniciales. A. Vista frontal. B. Vista lateral derecha. C. Manos

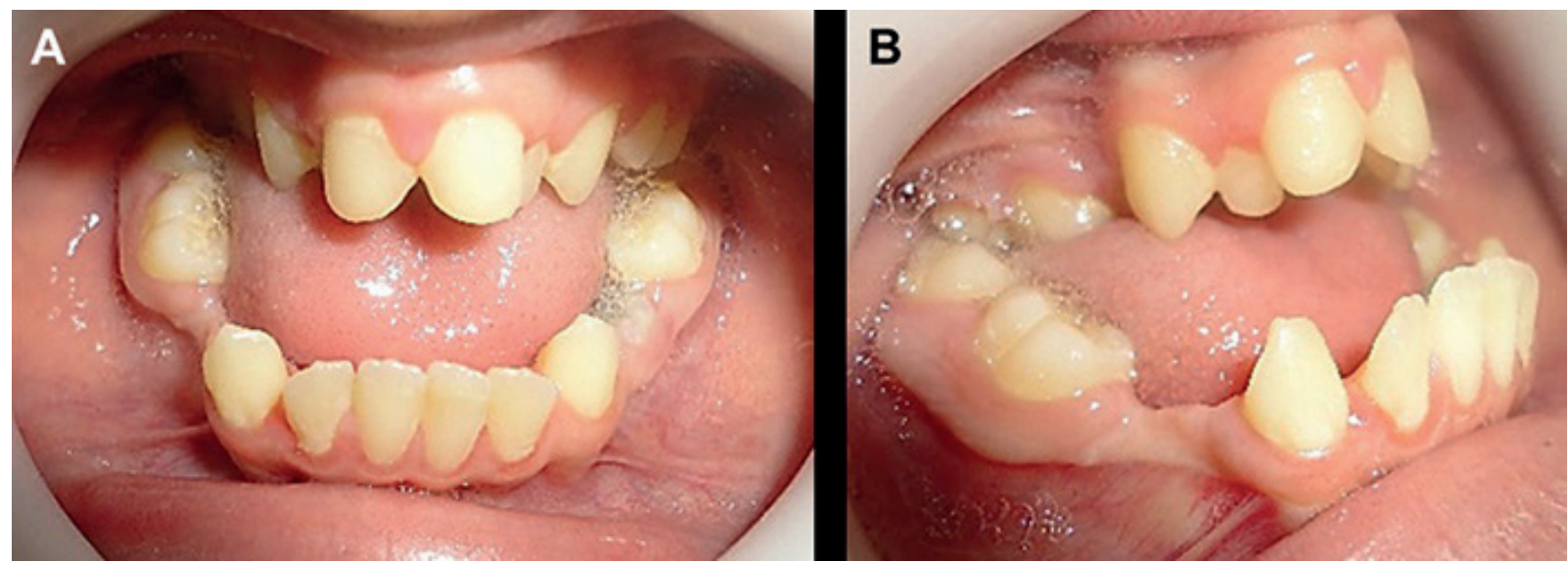

Figura 2. Fotografías intraorales iniciales. A. Vista frontal. B. Vista lateral derecha

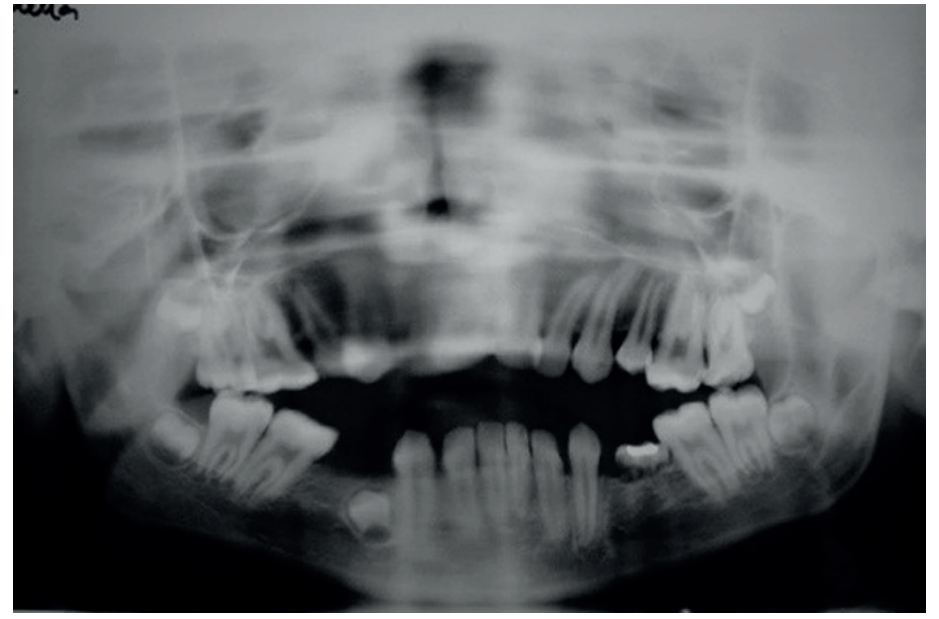

Figura 3. Ortopantomografía inicial 


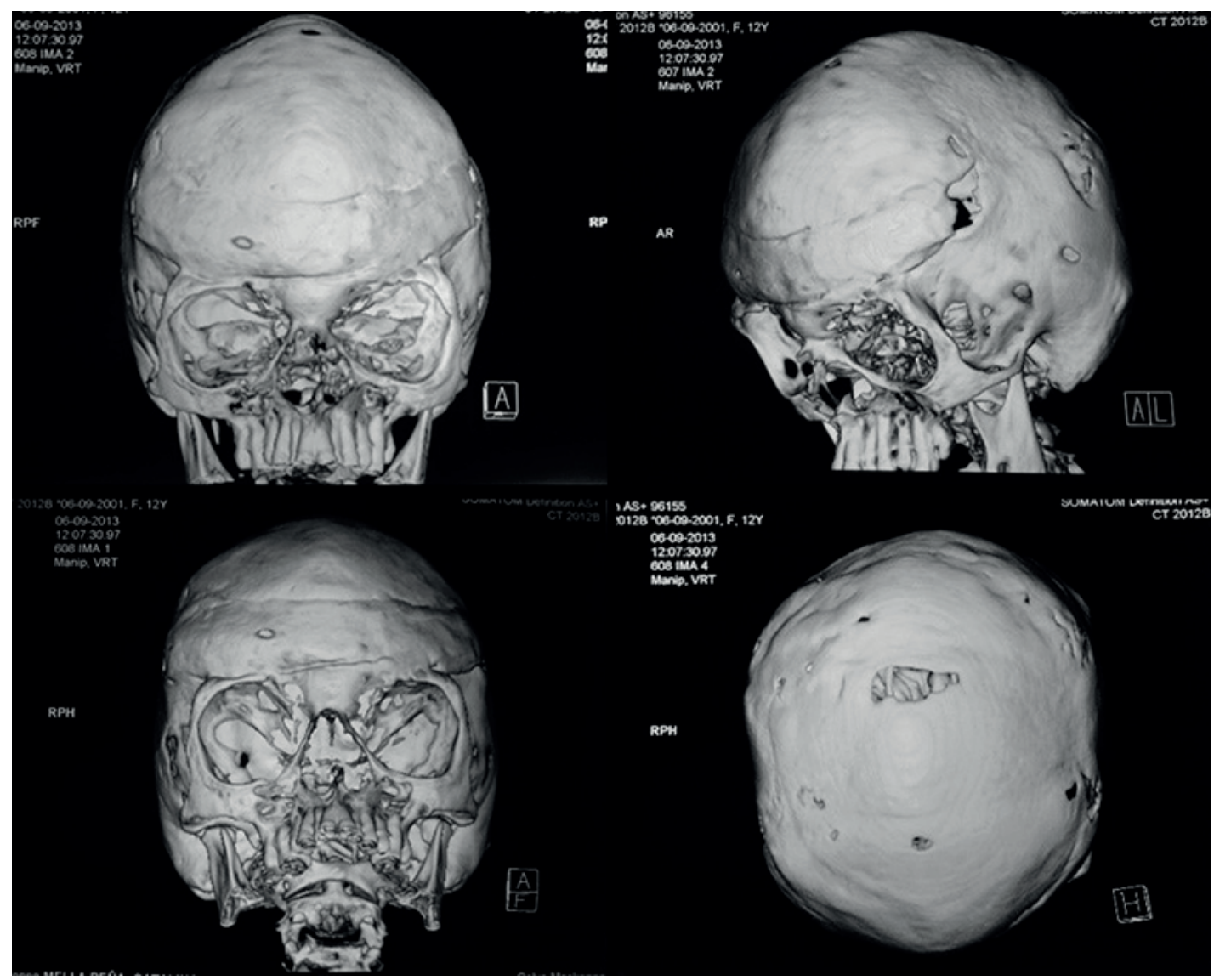

Figura 4. TCBB Reconstrucción 3D

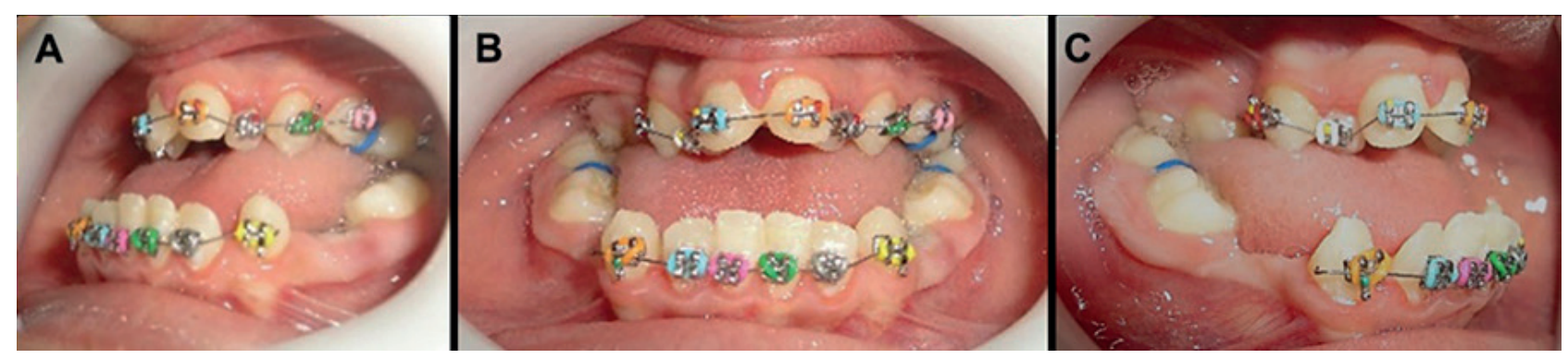

Figura 5. Inicio de tratamiento con aparatología fija. A. Oclusión vista lateral izquierda. B. Oclusión vista frontal. C. Oclusión vista lateral derecha
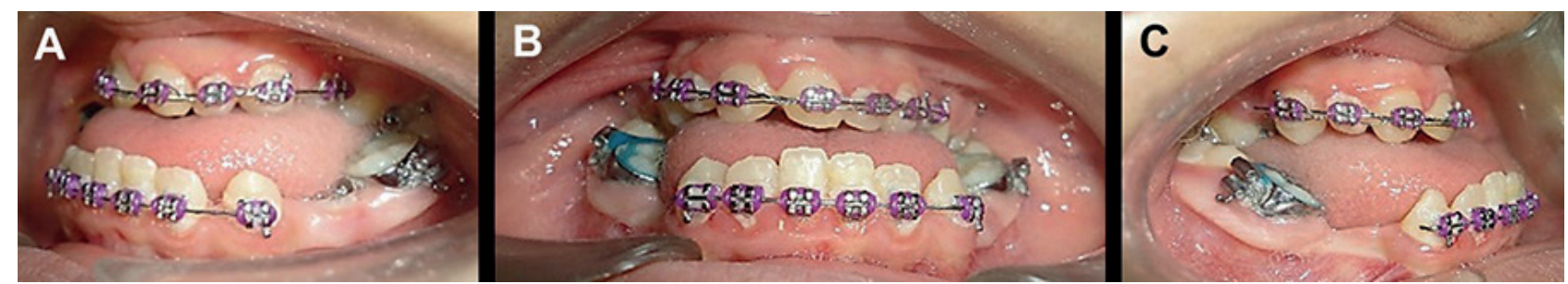

Figura 6. A los 12 meses tratamiento ortodóncico. A. Oclusión vista lateral izquierda. B. Oclusión vista frontal. C. Oclusión vista lateral derecha

ortodóncica fija para la finalización del caso. En una primera fase, se realizó una expansión lenta del maxilar utilizando un aparato removible con tornillo central, el cual fue usado durante todo el día y noche, excepto para comer. El protocolo utilizado fue de dos a tres activaciones por mes. Al cabo de 12 meses, se logró un aumento en el sentido transversal de $7 \mathrm{~mm}$.
Posteriormente, se instaló la aparatología ortodóncica fija en el arco superior e inferior (Figura 5). A los 30 meses de tratamiento, se logró una adecuada alineación y nivelación dentaria (Figura 6). En esta etapa, registros de modelos y fotográficos fueron realizados (Figura 7), con el fin de comenzar el estudio y programación del proceso de distracción osteogénica. A los 14 años la pa- 
ciente ingresó a evaluación y apoyo psicológico para la preparación quirúrgica.

Se confeccionó un splint intraoral con anclaje en las bandas de los dientes 1.6 y 2.6 (Figura 8), manteniendo arcos de ortodoncia de acero $0,017 \mathrm{x}$ 0,025 de canino superior derecho a canino superior izquierdo con multibrackets, para estabilizar los segmentos, debido a que el distractor tendría que utilizarse por un largo período de tiempo.

Se realizó osteotomía Le Fort I e instalación quirúrgica de un dispositivo distractor tipo Halo (RED) por parte del equipo máxilofacial. A las 24 horas post cirugía, se comenzó la activación, a razón de un milímetro al día, durante 15 días (Figura 9). El tercio medio de la paciente se distrajo en sentido anterior, hasta que se obtuvo una corrección de la proptosis, un perfil facial favorable y un overjet sobrecorregido de $3 \mathrm{~mm}$; el avance maxilar total logrado fue de $15 \mathrm{~mm}$.

La paciente continuó utilizando el distractor sin activar, como contención por 50 días, para consolidar el avance. Durante la activación del RED, se utilizaron fuerzas elásticas intermaxilares verticales inicial de 3/16" (medio) con anclaje en dientes 1.3-4.3 y 2.3-3.3, diez horas al día por un mes; luego se indicó el uso de elásticos 1/8" (pesado) de uso nocturno, vertical de canino a canino bilateral, para contrarrestar la posible rotación antihoraria del maxilar. Se mantuvo el tratamiento con aparatos fijos durante 18 meses, para lograr una mejor armonía dentaria y estabilidad oclusal (Figura 10); período después del cual se realizó la remoción de los brackets y se instalaron retenedores removibles tipo Hawley de uso nocturno. Un año después del tratamiento con distractor, fue realizada una rinoseptoplastía (Figura 11).

Seguimiento y resultado. Se realizaron controles mensuales durante 24 meses. Se cumplieron con los objetivos terapéuticos planteados inicialmente: corrección de la hipoplasia maxilar y proptosis ocular, obtención de overjet dentro de parámetros normales y oclusión más estable (Figura 12). Tanto la paciente como su familia se mostraron conformes con los resultados obtenidos, especialmente a nivel estético, ya que el aspecto facial influyó positivamente en el psicológico de la paciente, pudiendo enfrentar mejores situaciones sociales y a sus pares (Figura 13).

En la evalución 20 meses post tratamiento, la oclusión se obervó estable en los sentidos sagital, transversal y vertical, así como también su estética facial. Después de este periodo, la paciente fue dada de alta y fueron

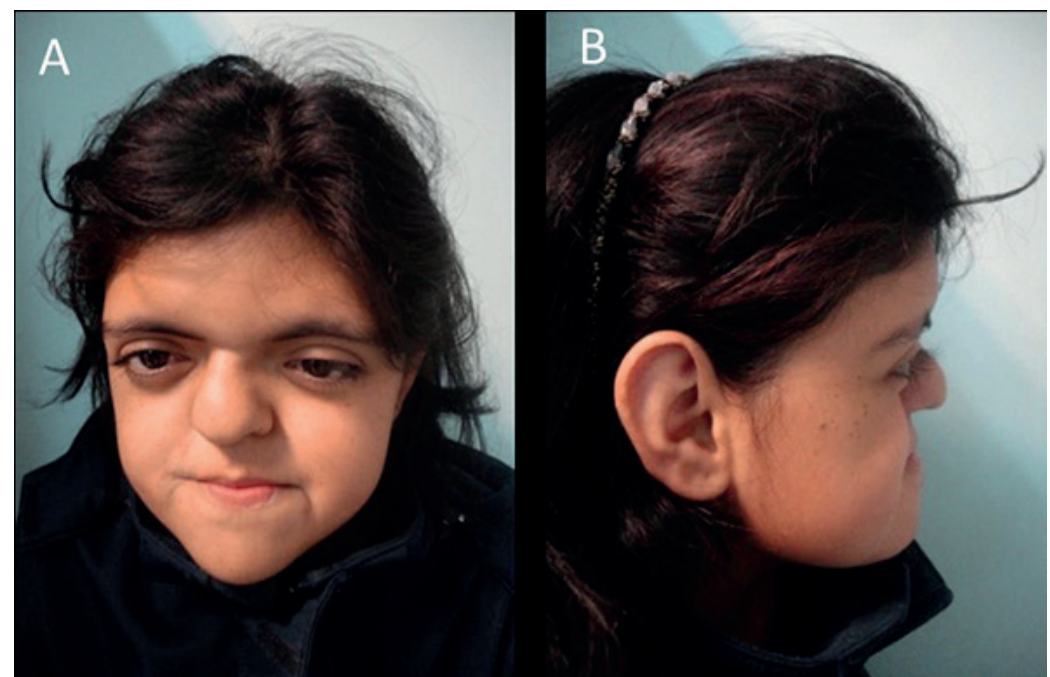

Figura 7. Fotografías extraorales post tratamiento ortodóncico. A. Vista Frontal. B. Vista lateral derecha

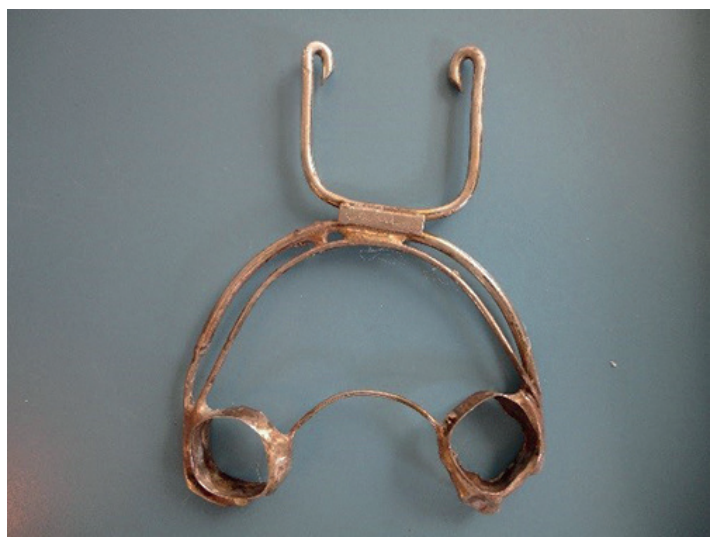

Figura 8. Splint intraoral para aparato RED

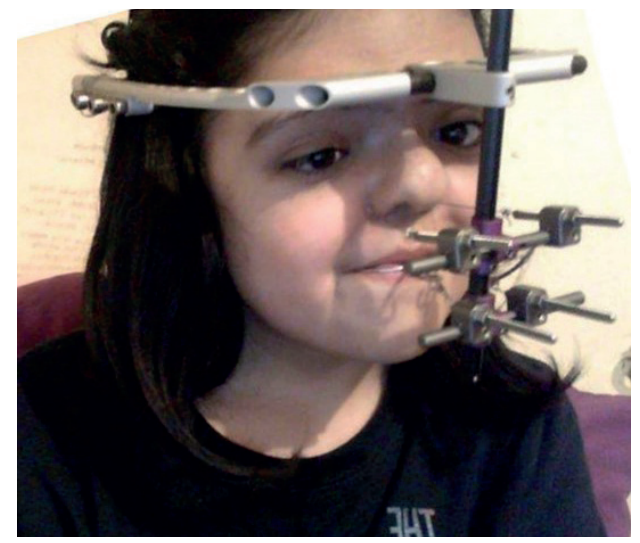

Figura 9. Distractor RED instalado 


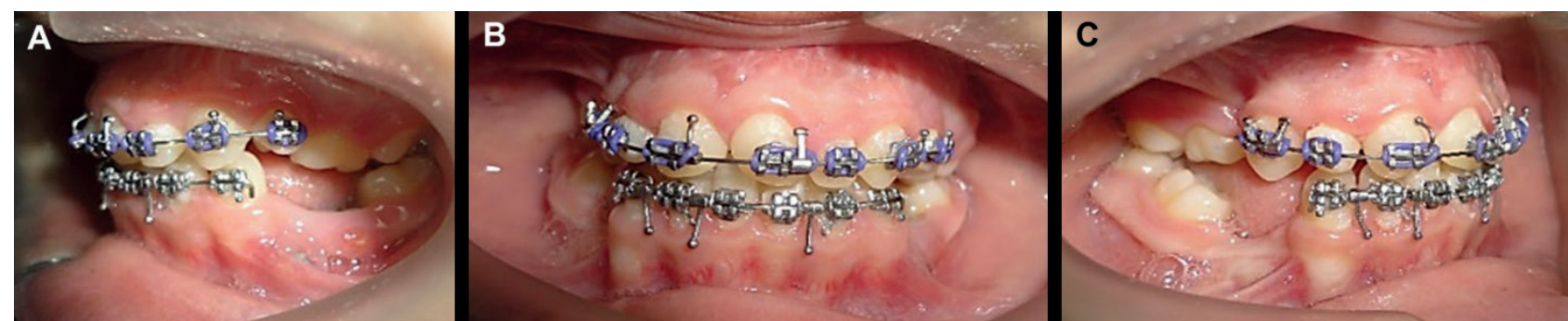

Figura 10. Fotografías intraorales post distracción osteogénica. A. Oclusión vista lateral izquierda. B. Oclusión vista frontal. C. Oclusión vista lateral derecha

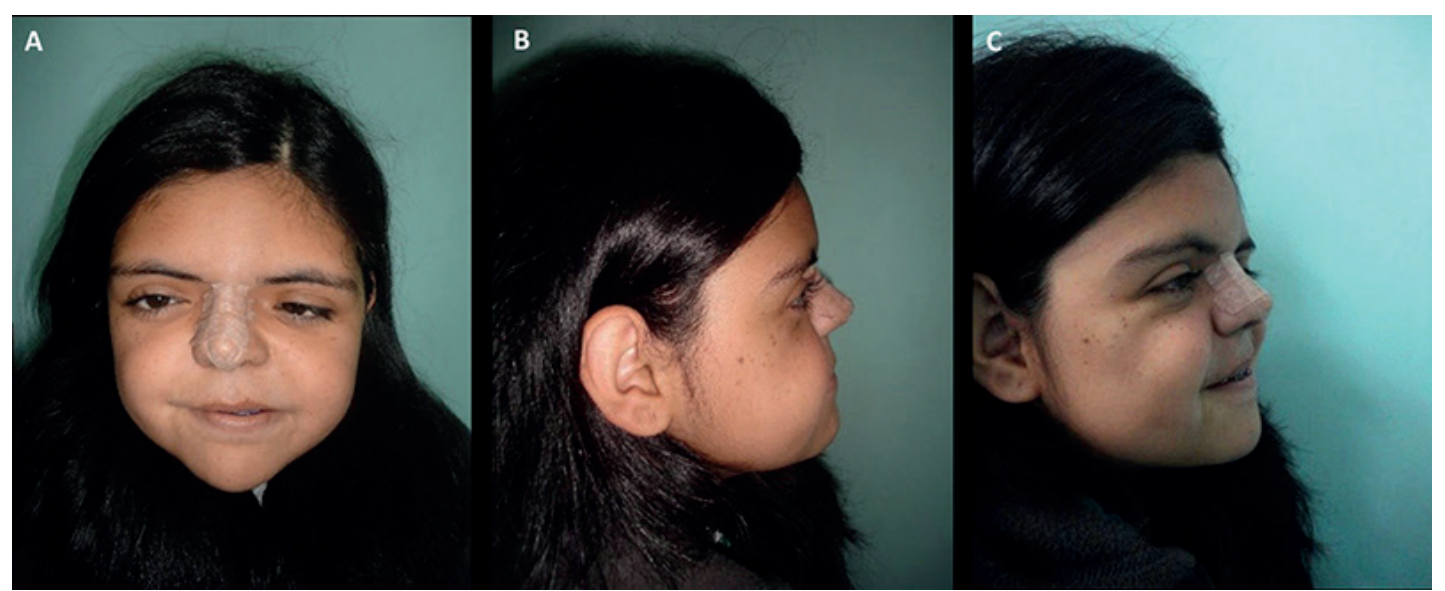

Figura 11. Fotografías extraorales post distracción osteogénica y rinoseptoplastía. A. Vista frontal. B. Lateral derecha. C. Lateral $45^{\circ}$

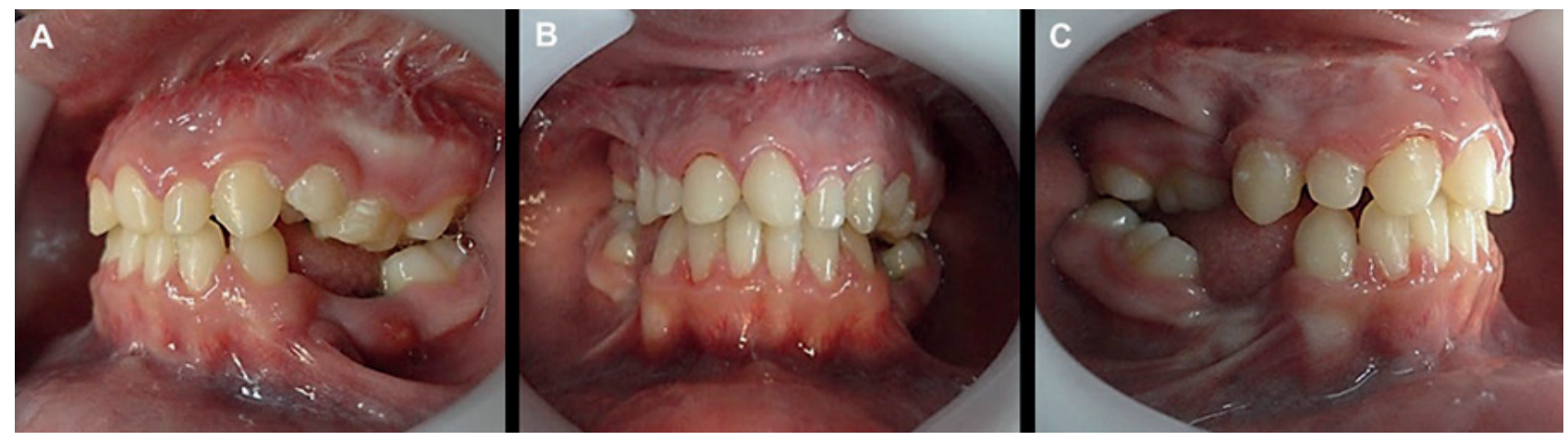

Figura 12. Fotografías intraorales post tratamiento. A. Oclusión vista lateral izquierda. B. Oclusión vista frontal. C. Oclusión vista lateral derecha

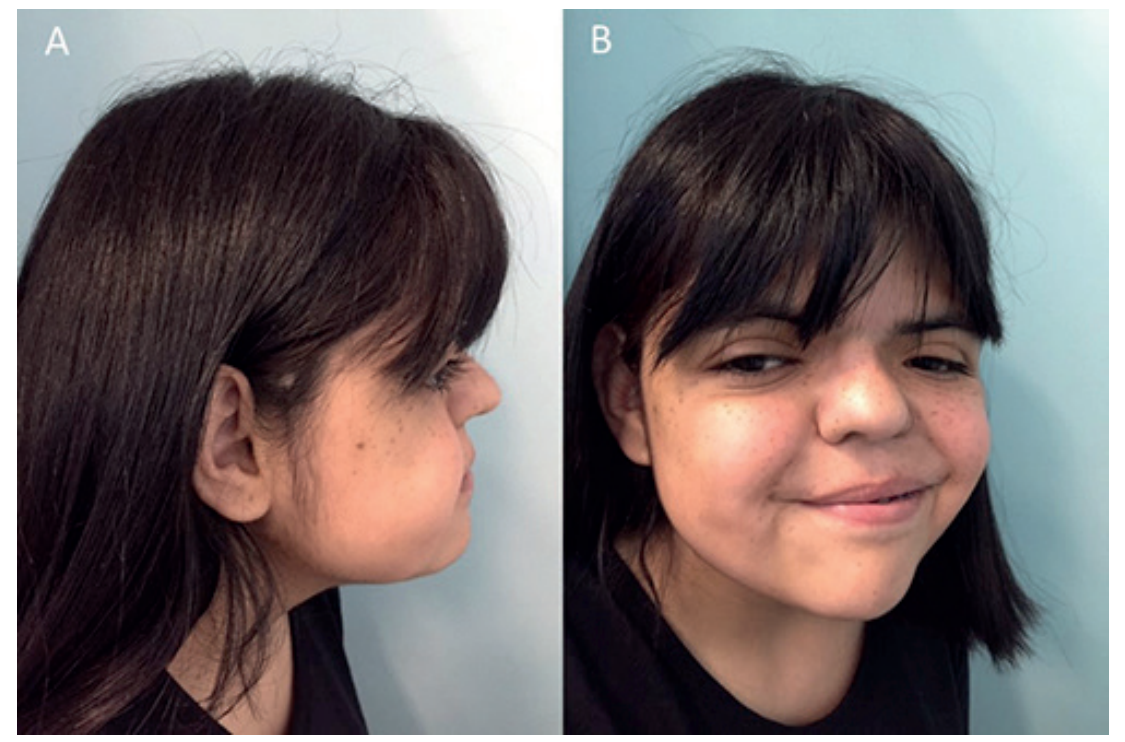

Figura 13. Fotografías extraorales post tratamiento. A. Vista frontal. B. Vista lateral derecha 
programados consultas más espaciadas para controlar y realizar el seguimiento de la paciente en largo plazo.

\section{Discusión}

El síndrome de Pfeiffer es una patología asociada a craneosinostosis, que se diagnostica en base a sus manifestaciones clínicas, tanto a nivel cráneofacial, como de extremidades superiores e inferiores. Hipoplasia del tercio medio, braquicefalia, proptosis ocular, falanges distales anchas y sindactilia parcial de manos y pies, son algunas de sus características más clásicas ${ }^{6}$.

Aunque la hipoplasia maxilar puede tratarse con cirugía ortognática convencional, esta tiene una serie de limitaciones; requiere que el paciente haya completado su crecimiento, solo puede realizarse cuando el avance requerido es menor a $10 \mathrm{~mm}$ y no permite el desarrollo adecuado del tejido blando adyacente ${ }^{11}$.

La distracción osteogénica es un procedimiento que puede ser utilizado para tratar la retrusión del tercio medio facial, ya que permite un gran avance óseo con una baja tasa de complicaciones ${ }^{12}$. Suele indicarse en casos de hipoplasia esqueletal severa en los tres sentidos del espacio y/o en pacientes en crecimiento.

En conjunto a la osteotomía Le Fort, esta técnica modifica la forma y volumen de la órbita, ya que permite el avance del complejo nasomaxilar, corrigiendo así la desproporción óculo-orbital presente en estos pacientes. En un estudio realizado por Arnaud et al. ${ }^{13}$, se determinó que este tratamiento, realizado en pacientes con síndrome de Pfeiffer y Apert, aumentaría el tamaño de la órbita, corrigiendo el exoftalmo y la proptosis; siendo esto demostrado mediante imágenes tridimensionales de cefalometría.

Otro beneficio descrito es la respuesta del tejido blando consecuente con la distracción del maxilar. Además, permite realizar sobrecorrección del defecto, reduciendo así la necesidad de realizar otros procedimientos a futuro y no requiere el uso de injerto óseo, ya que hay neo-formación de hueso ${ }^{14}$.

En el caso reportado, la paciente fue derivada a la especialidad de Ortodoncia a temprana edad. Por la severidad de la retrusión del tercio medio facial (mayor a diez milímetros) y por los problemas psicosociales que relataba la paciente, se escogió la distracción osteogénica como alternativa terapéutica. Aunque existen dispositivos de uso interno, los distractores externos, específicamente los RED, son los más utilizados por los cirujanos debido a sus múltiples ventajas: permiten longitudes mayores de distracción ósea, son multivectoriales en relación a la fuerza que aplican y son más fáciles de remover. Entre sus desventajas están que requieren un soporte óseo de buena calidad, pueden generan cicatrices a nivel de rostro y cráneo y un estigma social durante el período de su uso ${ }^{12}$.

Si bien la distracción osteogénica posee una menor tasa de recidiva en comparación a la cirugía ortognática, se recomienda programar una sobrecorrección anterior en un rango entre un $20 \%$ a un $30 \%$, sobre todo en pacientes en crecimiento ${ }^{15}$. Por esta razón se determinó que el avance maxilar requerido en la paciente fuera de $15 \mathrm{~mm}$, para una retrusión de $12 \mathrm{~mm}$ presentada por la paciente.

Los resultados clínicos obtenidos en el caso reportado se mantuvieron estables en la evaluación a los 20 meses post tratamiento. Gracias al uso de este protocolo de tratamiento, no fue necesario someter a la paciente a cirugía ortognática. En un estudio, Fearon ${ }^{16}$ realizó un seguimiento de 5 años a 41 pacientes sometidos a distracción con dispositivo Halo y osteotomía LeFort III, y reportó que el maxilar permaneció estable en su posición y no se observó crecimiento anterior durante ese período; concluyendo que la mayoría de los pacientes sometidos a este procedimiento, probablemente no requerirán otro avance maxilar similar a futuro.

Otros autores han reportado casos de pacientes con hipoplasia del tercio medio facial severa, causada por síndromes asociados a craneosinostosis, tratados exitosamente con distracción osteogénica y ortodoncia fija 5,17; resultados que coinciden con los descritos en este reporte.

Los pacientes con el síndrome de Pfeiffer poseen características dentofaciales típicas las cuales deben ser diangósticadas para ser tratadas en el momento oportuno. Es importante recalcar que la evaluación y tratamiento por parte de un equipo multidisciplinario comienza desde el nacimiento y la infancia, extendiéndose incluso hasta la adultez. La ortodoncia tiene como objetivo acompañar el crecimiento maxilar, evitar el cierre prematuro de la sutura intermaxilar y preparar al paciente para una cirugía maxilofacial en la adolescencia, a fin de mejorar la estética y la función ${ }^{18}$. Este reporte de caso demuestra que la hipoplasia media facial severa, causada por el síndrome de Pfeiffer se puede tratar exitosamente con distracción osteogénica del tercio medio facial asociada a aparatología ortodóncica fija.

\section{Referencias bibliográficas}

1. Roldán-Arce J, Villarroel-Cortés C. Síndrome de Pfeiffer tipo 2. Informe de un caso y revisión de la literatura. Acta Pediátrica de México. 2013;34(1):43-7.

2. Santana Hernández E, Tamayo Chang V. Pfeiffer syndrome. Presentation of an affected family. Medicentro Electrónica [Internet]. 2016 Mar [citado 2018 Dic 15]; 20(1):81-85. Disponible en: http://scielo.sld.cu/scielo.php?script=sci_arttext\&pid=S1029-30432016000100013\&lng=es.

3. Gómez L, Morales A, Salomón J, Berttolini AJ, Toledo E, Cornelio RM. Síndrome de Pfeiffer tipo 2 con expresividad variable. Bol Med Hosp Infant Mex. 2004;61:68-72.

4. Júnior HM, de Aquino SN, Machado RA, Leão LL, Coletta RD, Burle-Aguiar MJ. Pfeiffer syndrome: Clinical and genetic findings in five Brazilian families. Med oral patol oral cir bucal. 2015 Jan; 20(1):e52. DOI: https:// doi.org/10.4317/medoral.20032

5. Park Y, Hobar PC, Sinn DP, Peanchitlertkajorn S. Patient with Pfeiffer's syndrome treated by midfacial distraction and comprehensive orthodontics. Am J Orthod 
Dentofacial Orthop. 2011 Feb 1; 139(2):260-70. DOI: https://doi.org/10.1016/j.ajodo.2010.06.020

6. Hassona Y, Al-Hadidi A, Ghlassi TA, Dali HE, Scully C. Pfeiffer syndrome: oral healthcare management and description of new dental findings in a craniosynostosis. Spec Care Dentist. 2017 Sep; 37(5):258-62. DOI: https://doi.org/10.1111/scd.12236

7. Navazo- Eguía AI, Suárez-Muñiz E, García-Vicario F, de la Mata- Franco G, Suárez Fernández J, Gómez-Sáez F. Síndrome de Pfeiffer. A propósito de un caso. Rev Soc Otorrinolaringol. 2011;2(8):1-8

8. Buchanan EP, Xue AS, Hollier Jr LH. Craniofacial syndromes. Plast Reconstr Surg. 2014 Jul 1; 134(1):128e-53e. DOI: https://doi.org/10.1097/prs.0000000000000308

9. Polley JW, Figueroa AA. Management of severe maxillary deficiency in childhood and adolescence through distraction osteogenesis with an external, adjustable, rigid distraction device. J Craniofac Surg. 1997;8(3):181-185.

10. Meling TR, Hogevold HE, Due-Tonnessen BJ, Skjelbred P. Midface distraction osteogenesis: Internal vs. external devices. Int J Oral Maxillofac Surg. 2011;40:139-45. DOI: $10.1016 /$ j.ijom.2010.10.009

11. Cheung LK, Chua HD, Hägg MB. Cleft maxillary distraction versus orthognatic surgery: clinical morbidities and surgical relapse. Plast Reconstr Surg. 2006;118(4):9961008. DOI: 10.1097/01.prs.0000232358.31321.ea.

12. Goldstein JA, Paliga JT, Taylor JA, Bartlett SP. Complications in 54 frontofacial distraction procedures in pa- tients with syndromic craniosynostosis. J Craniofac Surg. 2015 Jan 1;26(1):124-8. DOI: https://doi.org/10.1097/ scs.0000000000001320

13. Arnaud E, D. Marchac D, Renier D. Distraction osteogenesis with double internal devices combined with early frontal facial advancement for the correction of facial craniosynostosis. Report of clinical cases. Ann Chir Plast Esthet. 2001 Aug; 46(4):268-76. DOI: https://doi. org/10.1016/S0294-1260(01)00043-7

14. Aizenbud D, Rachmiel A. Midface distraction osteogenesis complication: intracranial penetration of a rigid external distraction system pin. Plast Reconstr Surg 2008;121: 216e-217e. DOI: 10.1097/01. prs.0000305380.89782.2b

15. Cho BC, Kyung HM. Distraction osteogenesis of the hypoplastic midface using a rigid external distraction system: the results of a one- to six-year follow-up. Plast Reconstr Surg 2006;118:1201-1212. DOI: 10.1097/01. prs.0000243563.43421.0b

16. Fearon JA. Halo distraction of the Le Fort III in syndromic craniosynostosis: a long-term assessment. Plast Reconstr Surg 2005;115:1524-36.

17. Miyazaki H, Katada H, Ichinokawa Y, Hirabayashi S, Sueishi K. Orthodontic treatment in combination with Le Fort II bone distraction in patient with Apert syndrome. Bull Tokyo Dent Coll. 2013;54(1):9-17. DOI: https://doi.org/10.2209/tdcpublication.54.9

18. Hoyos Serrano M. Síndrome de Crouzon. Rev Act Clín Med. 2014 Jul;46:24-57 